\title{
In-Service Oxidation and Microstructural Evolution of a Nickel Superalloy in a Formula 1 Car Exhaust
}

\author{
S. Pedrazzini ${ }^{1}$ (D) E. S. Kiseeva ${ }^{2}$ R. Escoube ${ }^{2}$ - H. M. Gardner ${ }^{3}$. \\ J. O. Douglas ${ }^{3}$ - A. Radecka ${ }^{4}$ - P. M. Mignanelli ${ }^{1}$ - G. M. Hughes ${ }^{3}$. \\ G. Chapman ${ }^{3}$ - P. D. Edmondson ${ }^{5}$ H. J. Stone ${ }^{1}$ - D. De Lille ${ }^{6}$. \\ P. A. J. Bagot $^{3}$
}

Received: 25 May 2017/Revised: 28 July 2017

(c) The Author(s) 2017. This article is an open access publication

\begin{abstract}
The oxidation response and microstructural evolution of an Inconel 625 alloy exhaust manifold exposed to an automobile racing environment has been examined using a range of advanced electron microscopy-based techniques, atom probe tomography and high-sensitivity laser ablation mass spectrometry. The dynamic, corrosive gas conditions result in accelerated oxidation, with the inner exhaust surface also heavily contaminated by multiple species including Zn, P, K and $\mathrm{Na}$. $\mathrm{Nb}$ carbides and Ti nitrides identified in stock control samples evolve into mixed $(\mathrm{Ti}, \mathrm{Nb}) \mathrm{N}$ species during exposure, decorated by smaller Mo, Si-rich precipitates. The exposed alloy component therefore reveals unique surface and subsurface features following in-service use.
\end{abstract}

Keywords Nickel-based superalloys · Corrosion · Oxidation · Atom probe tomography

Electronic supplementary material The online version of this article (doi:10.1007/s11085-017-97927) contains supplementary material, which is available to authorized users.

\section{S. Pedrazzini}

sp856@cam.ac.uk

1 Department of Materials Science and Metallurgy, University of Cambridge, 27 Charles Babbage Road, CB3 0FS Cambridge, UK

2 Department of Earth Sciences, University of Oxford, South Parks Road, Oxford OX1 3AN, UK

3 Department of Materials, University of Oxford, Parks Road, Oxford OX1 3PH, UK

4 Rolls Royce plc, P.O. Box 31, Derby, UK

5 Oak Ridge National Laboratory, Materials Science and Technology Division, Oak Ridge, TN 37831, USA

6 Good Fabrications Ltd, Long Crendon, Aylesbury HP18 9BA, UK 


\section{Introduction}

Ni-based superalloys have established themselves as vital materials in demanding operating environments requiring structural integrity under high-stress and hightemperature conditions. These environments are typically present in gas turbines for aerospace, marine propulsion and fixed-installation power generation $[1,2]$. There has also been recent interest in developing Ni-based superalloys for applications in the engine and exhaust sections of automobiles to replace the steels currently used [3]. The motivation for doing this is the greatly improved corrosion resistance of superalloys, along with the better retention of mechanical properties at elevated temperatures. Applications within this sector are likely to grow owing to demands for fuel-efficient and lean-burn combustion engines and for higher-performance vehicles, both of which generate increased exhaust temperatures, which can exacerbate corrosion problems. A comprehensive understanding of alloy response in such environments is required to meet this demand.

Inconel 625 (Special Metals Corporation) is a nickel-chromium superalloy developed for applications where corrosion resistance is especially important. It benefits from substantial solid solution strengthening and can be precipitationhardened at elevated temperatures to produce coherent, ordered $\gamma^{\prime \prime} \mathrm{Ni}_{3}(\mathrm{Nb})$ or incoherent, hexagonal close-packed $\delta \mathrm{Ni}_{3}(\mathrm{Nb})$ phases. It is also formable and readily weldable, making it well suited for the fabrication of complex structures such as exhaust tubing.

As with other superalloys, operation of Inconel 625 in corrosive/oxidising conditions can lead to component failure, either directly through mass loss (spallation of material) or indirectly through environmentally assisted crack propagation $[4,5]$. To understand such effects, previous studies on this and similar alloys have examined oxidation and surface degradation behaviour using a variety of model exposures [6-11]. The benefits of protective coatings have also been studied [12, 13], along with the effects of corrosion following exposure to salts simulating gas turbine [14] and fuel cell [15] operation. All of these studies were carried out under carefully controlled laboratory conditions, designed to mimic the environment experienced in-service, and offer valuable insights into the alloy response. However, the real in-service conditions are more complex. Thermal spikes and constant variations during acceleration and deceleration of the car will occur. In addition, different gas-phase contaminants, including air, combustion by-products (water vapour, $\mathrm{CO}_{2}$ ) and fuel additives, will react with the exhaust surface. As such, the in-operando environment comprises transient, dynamic exposures to a variety of thermal and corrosive extremes. Some of the experimental conditions could be simulated in a laboratory, using a pressurised charging cell [16] in a furnace with a feedback loop which increases the pressure when the temperature is raised. It would have to then be programmed to go through random cycles of "acceleration" and "deceleration" similar to real-engine conditions. Such a setup would be extremely difficult to create due to the harsh, corrosive nature of the contaminants and temperatures involved $\left(5-7\right.$ bar at $\left.650-1000{ }^{\circ} \mathrm{C}\right)$. Inconel 625 is one of the most corrosion-resistant alloys available; therefore, the entire charging cell and inner 
furnace components (including high-vacuum chambers, connectors, flanges, bolts, etc.) would have to be made of Inconel 625 or a similar alloy. Several safety precautions would have to be taken, such as pressure gauges, leak detectors, fire arrestors, relief valves, safe disposal of corrosive compounds, etc. Designing and building such a custom-made apparatus would be costly and inefficient. In addition, the environmental contaminants would be difficult to predict and simulate. Proximity to the sea would increase the levels of chlorine, racing in a desert would increase the likelihood of silica (sand) particles entering the engines and their incidence would also depend highly on the local weather and atmospheric conditions, which would also have to be reproduced in order to accurately simulate the operating environment. It is therefore preferable to analyse ex-service components, using advanced characterisation tools that combine high spatial resolution with the ability to identify all of the elements and species present. The large number of elements present in superalloys poses inherent issues for their analysis, in addition to species in the environment that may attack the metal surfaces.

Despite the complexities associated with examining in-service systems, example studies on Inconel 625 are now emerging, specifically focused on failure analysis in an automotive exhaust [17] and ammonia cracking [18] applications. In this paper, a combination of advanced analytical methods were used to characterise the surface and near-surface behaviours of an Inconel 625 exhaust manifold that had been used within an in-service environment of a Formula 1 automobile. These intricate, handbuilt exhaust structures are closely coupled to hot running engines, and the short lifetime of these components in such aggressive environments necessitates frequent replacement. In the current work, we firstly aim to address the questions posed above concerning real versus model exposures for this particular alloy. Secondly, we have sought to identify areas where modifications to composition, processing or the overall engine system may lead to improvements, both in the development of more representative model studies and in quantifiable component performance/ lifetime gains, relevant to a range of applications.

\section{Experimental Procedures}

All analysed material was supplied by Good Fabrications Performance Exhausts Ltd., using sheet material provided by Special Metals. The sheet had been coldrolled and pickled to remove surface impurities before annealing at $1040{ }^{\circ} \mathrm{C}$. The composition of the stock material was determined by X-ray fluorescence (Table 1). All elements are within the nominal specification for Inconel 625.

Table 1 Composition of Inconel 625 as determined by X-ray fluorescence

\begin{tabular}{|c|c|c|c|c|c|c|c|c|c|c|}
\hline at. $\%$ & $\mathrm{Ni}$ & $\mathrm{Cr}$ & $\mathrm{Fe}$ & Mo & $\mathrm{Nb}$ & Co & $\mathrm{Mn}$ & $\mathrm{Al}$ & $\mathrm{Ti}$ & $\mathrm{Si}$ \\
\hline & Bal. & 25.1 & 4.8 & 5.5 & 2.3 & 0.2 & 0.1 & 0.6 & 0.5 & 0.2 \\
\hline
\end{tabular}


The exhaust manifold had been exposed to engine exhaust gas/particulates throughout its operational lifetime in a highly dynamic transient cycle of an auto racing (Formula 1 car) environment. The total in-service duty cycle across a number of races was $33 \mathrm{~h}$, between which all components cooled and were stored at room temperature. During service, the exhaust can operate at temperatures ranging between $\sim 650$ and $1000{ }^{\circ} \mathrm{C}$ and pressures around 5 bar ( 7 bar peak). The $1.75 \mathrm{~mm}$-thick tube section provided was $50 \mathrm{~mm}$ long and $40 \mathrm{~mm}$ in diameter and removed from an exhaust manifold installed approximately $100 \mathrm{~mm}$ downstream from the engine block. From this, small square samples $(10 \times 10 \mathrm{~mm})$ were sectioned for metallographic examination, using a low-speed diamond saw to avoid damaging the oxide scales. These were cold-mounted using epoxy resin, polished to $1 \mu \mathrm{m}$ diamond finish and coated with $20 \mathrm{~nm}$ carbon to improve conductivity and reduce beam drift in electron microscopes. Cross sections from both the inner exhaust surface (i.e. exposed to engine exhaust gases) and the outer exhaust surface (exposed only to air at high temperature) were examined. Strips of unused Inconel 625, also supplied by Good Fabrications as control samples, were mounted and polished according to the same procedure.

Scanning electron microscopy (SEM) was performed in the David Cockayne centre for Electron Microscopy, University of Oxford, using a Zeiss NVision dualbeam microscope with focussed ion beam (FIB) capability, and a Zeiss Merlin equipped with an Oxford Instruments $\mathrm{Xmax}^{\mathrm{N}} 150$ energy dispersive $\mathrm{X}$-ray spectroscopy detector (EDX). SEM images/EDX maps were obtained at $10 \mathrm{kV}$, while EDX maps were processed using Oxford Instruments Aztec software using the TruMap algorithm to background-correct and deconvolute peaks. Composition values quoted were obtained using the Cliff-Lorimer method [19]. Electron probe microanalysis (EPMA) was performed using two instruments: a JEOL JXA-8800 (operated at $25 \mathrm{kV}, 30 \mathrm{nA}$ ) in the Oxford Materials Characterisation Services (OMCS) laboratory, Begbroke Science Park, and a Cameca SX100 (operated at $15 \mathrm{kV}, 60 \mathrm{nA}$ ) in the University of Edinburgh.

Samples were prepared for atom probe tomography (APT) analysis using two methods. For site-specific analyses, a Helios NanoLab 600 SEM-FIB microscope equipped with an Omniprobe micromanipulator at Imperial College, London, was used to prepare samples following the standard lift-out method [20], using the Ga beam to mill out, extract, mount (onto a standard Cameca Si-flat top coupon) and finally sharpen the resulting tips, each of end diameter $<100 \mathrm{~nm}$. For bulk analyses, strips of unused Inconel 625 (15 mm long) were electropolished in $10 \mathrm{vol} \%$ perchloric acid/acetic acid solution and then finished in a solution of $2 \mathrm{vol} \%$ perchloric acid in butoxyethanol to produce suitably sharp needle-shaped samples. All samples were analysed using a Cameca LEAP 3000 HR system available in the Department of Materials, University of Oxford, with a specimen temperature of $50 \mathrm{~K}$, using laser mode $(0.3 \mathrm{~nJ})$ for fragile oxide-metal interfaces or voltage mode ( $25 \%$ pulse fraction) for bulk samples. All data sets were collected and processed using IVAS 3.6.14 software.

X-ray diffraction (XRD) was performed in the Department of Materials Science and Metallurgy, University of Cambridge, using a Bruker D8 Advance $\theta-2 \theta$ diffractometer operated at $40 \mathrm{kV}, 40 \mathrm{~mA}$, with $\mathrm{Cu}-\mathrm{K} \alpha$ radiation between $10^{\circ}$ and 
$50^{\circ} 2 \theta$ and using steps of $0.02^{\circ}$ with a dwell time of $7 \mathrm{~s}$. Diffractograms were processed using Bruker TOPAS software, by comparing them to theoretical spectra acquired through the Inorganic Crystal Structure Database ${ }^{1}$ (C) FIZ Karlsruhe).

Trace species analysis was performed by laser ablation-inductively coupled plasma mass spectrometry (LA-ICPMS), using a Perkin Elmer Nexion quadrupole mass spectrometer coupled to a New Wave Research UP213 Nd:YAG laser (50-100 $\mu \mathrm{m}$ spot size) available in the Department of Earth Sciences, University of Oxford. NIST 610 glass was used as the primary standard, while NIST 612 and USGS BCR-2G materials were used as secondary standards to monitor calibration accuracy.

\section{Results}

\section{Oxide Structure and Surface Segregation Behaviour}

Figure 1a shows a low-magnification backscattered electron (BSE) image of a cross section through the oxidised inner exhaust surface. The surface oxide is visible, penetrating into the alloy, particularly along grain boundaries. Below a featureless precipitate-free zone roughly $7-8 \mu \mathrm{m}$ deep, a number of other phases can be seen. Most of these are small $(<1 \mu \mathrm{m}$ dia.), along with less common instances of noticeably larger $(\sim 3 \mu \mathrm{m})$ block-shaped precipitates. The BSE image of Fig. 1b was taken from an unused section of Inconel 625 for comparison. This cross section was prepared by FIB machining and shows an oxide-free microstructure, with only a few of the larger bulk precipitates. Figure 1c is an equivalent BSE image from a FIB-machined cross section of the oxidised inner exhaust. The clear contrast between grains demonstrates that the smaller precipitates are almost exclusively located at grain boundaries. A large $(2-3 \mu \mathrm{m})$ void in the alloy is also located near the surface (see supporting movie).

EPMA analysis was conducted on cross sections of both the inner and outer exhaust surfaces to explore elemental distributions. Figure 2 shows EPMA maps from the inner surface.

The oxide layer is approximately $10-15 \mu \mathrm{m}$ thick, containing regions locally rich in many of the alloying elements. Below the thicker, outermost oxide layer, a thin Cr-enriched layer is present, beneath this a Si-rich layer and then discrete Al-rich regions protrude into the bulk. The latter correlate with the dark imaging regions in Fig. 1. Deeper below the surface, there are isolated $\mathrm{Nb}$, Ti-rich particles, and numerous smaller Mo, Si-rich features which correlate with the lighter-imaging regions in the SEM images at the grain boundaries. The Mo, Si-rich features in particular lie under the precipitate-depleted zone.

The maps for the exhaust outer surface are shown in Fig. 3. A thinner surface oxide is apparent from the oxygen map, only $2-3 \mu \mathrm{m}$ thick. At the base of the oxide is a $\mathrm{Cr}$-rich layer; beneath this there are isolated Al- and $\mathrm{Nb}$, Ti-rich features. The microstructure below the oxide is thus very similar to that of the inner surface,

\footnotetext{
1 icsd.cds.rsc.org.
} 


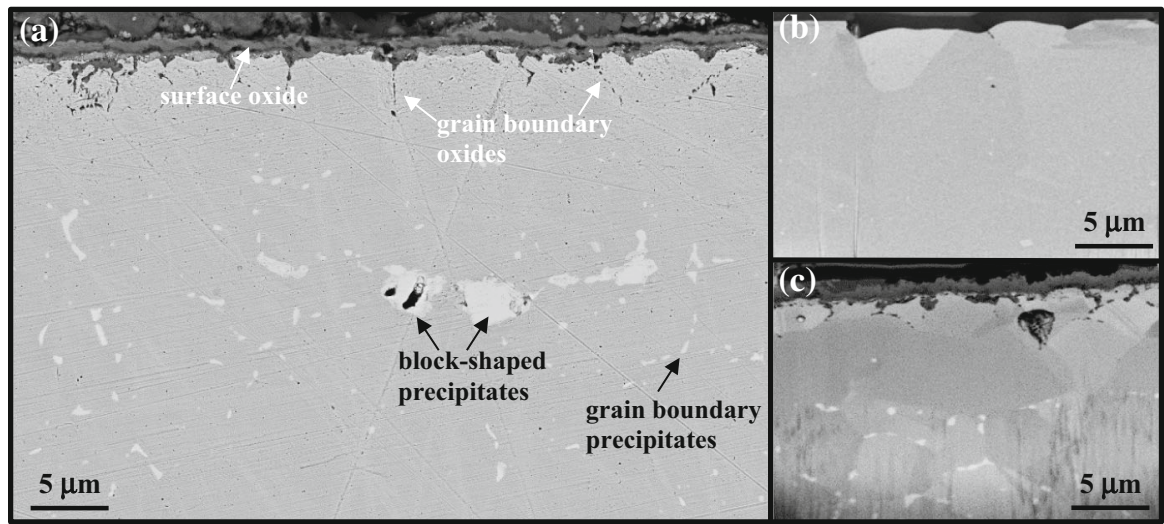

Fig. 1 SEM cross-sectional micrographs of Inconel 625 exhaust: a BSE image of oxidised inner surface, showing surface oxide scale, grain boundary oxide inclusions and subsurface precipitates, b BSE image of FIB-sliced unused exhaust, $\mathbf{c}$ BSE image of FIB-sliced oxidised inner exhaust surface showing surface oxide, a near-surface void and precipitates located at grain boundaries (FIB-slicing movie available as supporting information)

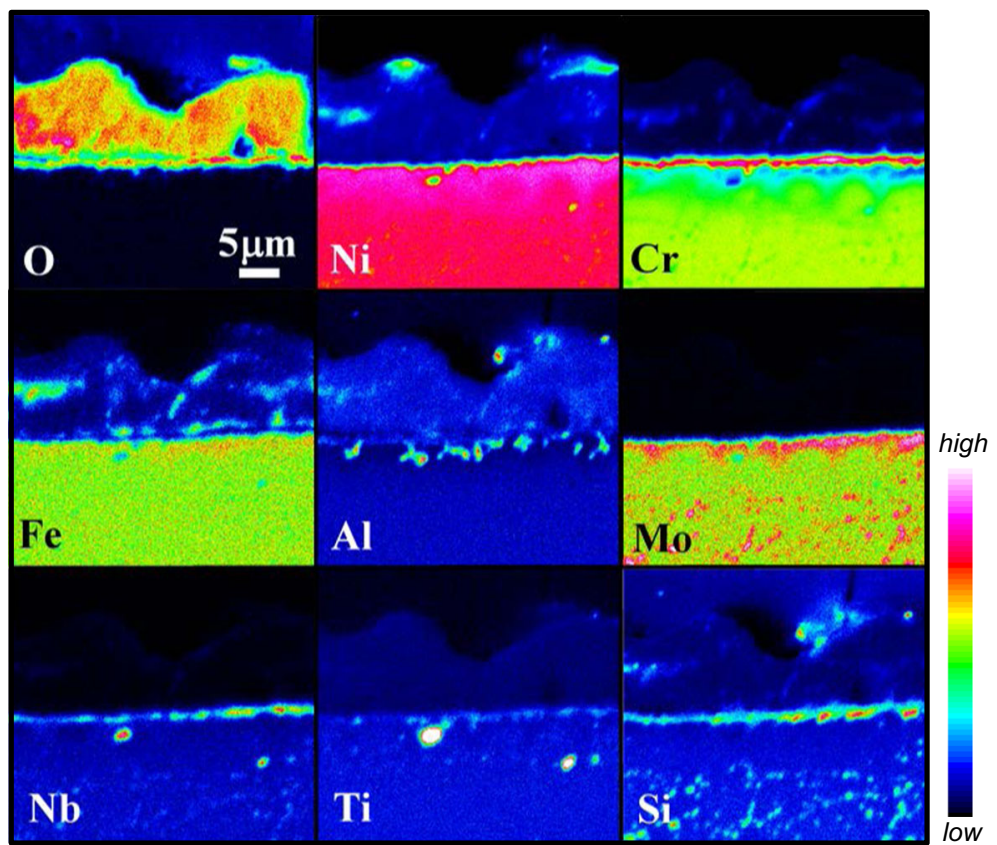

Fig. 2 EPMA elemental maps from exhaust inner surface

although with only slight $\mathrm{Si}$ enrichment beneath the oxide, and Mo, Si-rich precipitates decorating the grain boundaries in multiple locations some $\sim 5-6 \mu \mathrm{m}$ below the surface. 


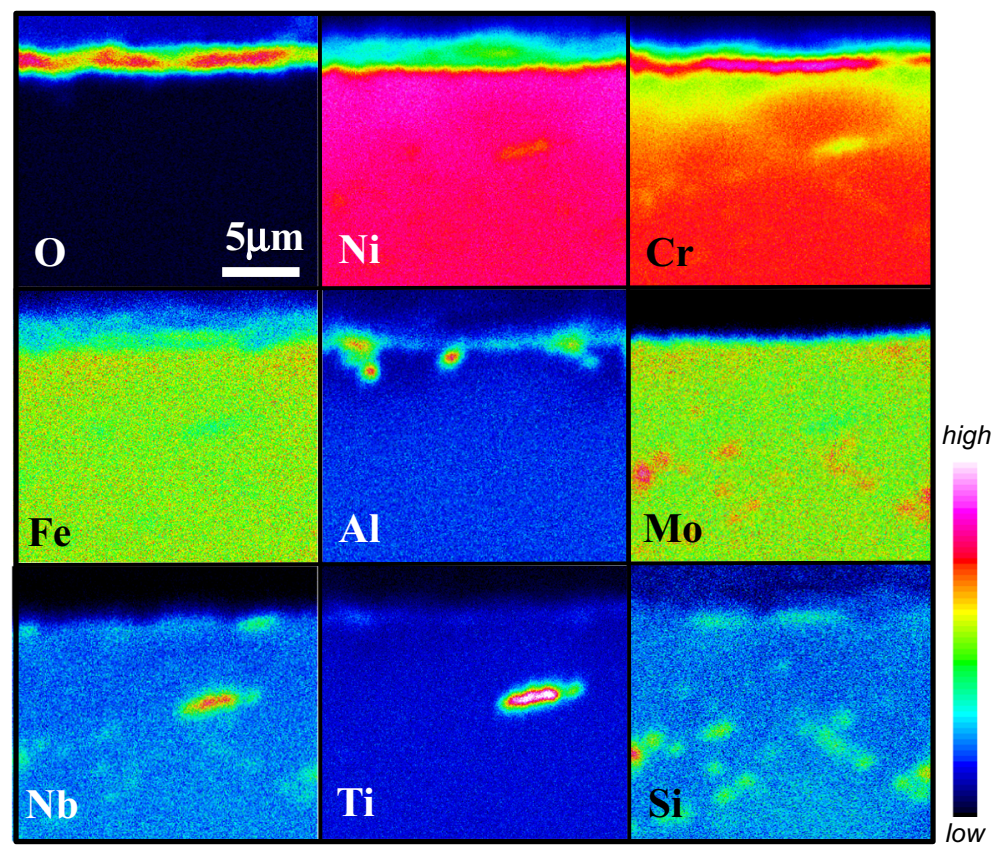

Fig. 3 EPMA elemental maps from exhaust outer surface

To complement the maps, semiquantitative point profile scans were conducted over the same near-surface region mapped in Fig. 2, and also in a separate scan deeper below the surface. Both of these are shown in Fig. 4.

In the near-surface scan of Fig. $4 \mathrm{a}$, a continuous $\mathrm{Cr}$ oxide layer, $\sim 5 \mu \mathrm{m}$ thick, is clearly identifiable under the main oxide layer. Below it lies a Cr-depleted region, indicative of $\mathrm{Cr}$ movement to the surface from the bulk. The levels of Mo and $\mathrm{Fe}$ appear constant, but within the $\mathrm{Cr}$-depleted region strong $\mathrm{Nb}$ enrichment is seen; the bulk content is only 2 at. $\%$ but peaks at $\sim 30$ at. $\%$ here. The deeper scan in Fig. $4 \mathrm{~b}$ carried out on separate EPMA instrument commences within the Cr-depleted
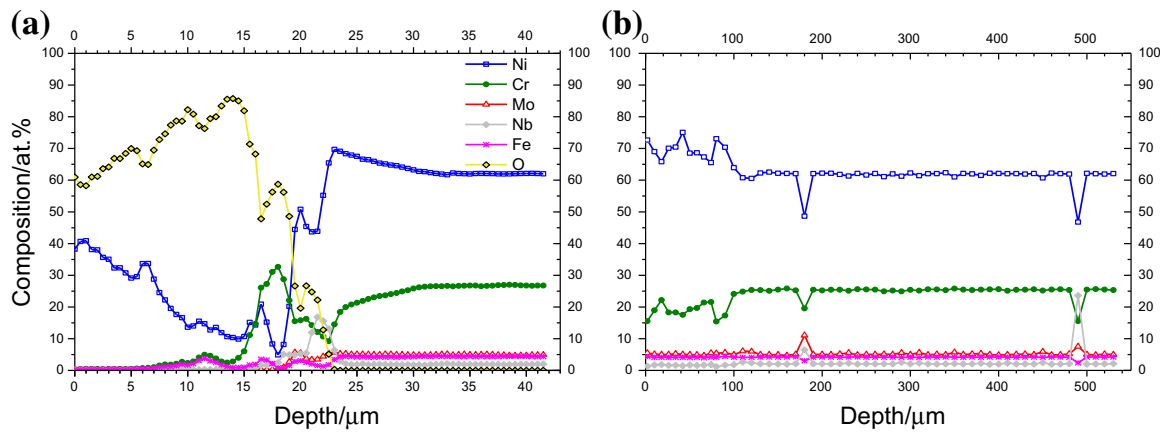

Fig. 4 EPMA point profiles a through inner exhaust oxide-metal interface, $\mathbf{b}$ into bulk 
region. Importantly, there is good agreement between the alloy compositions determined by both instruments away from the samples surfaces. Of more interest in Fig. $4 \mathrm{~b}$ is the presence of two isolated points, one where the composition deviates markedly towards strong enrichment of Mo and another $\mathrm{Nb}$; at $\sim 0.5 \mathrm{~mm}$ below the surface, one spot analysis contains $\sim 25$ at. $\% \mathrm{Nb}$. These again correspond closely with similar features visible in the maps, highlighting that they penetrate to a considerable depth below the alloy surface. A detailed examination of these specific features is presented in the following sections.

X-ray diffractograms of the inner and outer exhaust surfaces are shown in Fig. 5a, b, respectively. The presence of the bulk $\alpha$ phase nickel matrix and a small fraction of the orthorhombic $\delta$ phase were confirmed in both scans, as well as $\mathrm{Cr}_{2} \mathrm{O}_{3}$ oxide and $\mathrm{NiCr}_{2} \mathrm{O}_{4}$ spinel. The inner exhaust surface was, however, shown to contain a phase which was identified as $\mathrm{ZnS}_{6} \mathrm{PO}_{3} \mathrm{R}$, with $\mathrm{R}$ consisting of different alkyl groups, in this instance $\mathrm{C}_{39} \mathrm{H}_{29}$. Contamination on the exhaust inner surface will be further discussed in the following section.

To examine the oxide-metal interface at a higher resolution, APT samples were extracted from this region of the inner exhaust surface by the FIB lift-out method. Separately, the composition of the alloy was checked using one of the Inconel strips, preparing the samples by electropolishing (Table 2). The APT analysis of the FIBprepared exhaust samples is shown in Fig. 6, with atom maps on the left highlighting the nature of two different regions of oxide-metal interfaces examined, along with associated proximity histograms (proxigrams) on the right plotting the concentration of species detected on either side of the defined interfaces.

The APT data sets reveal a number of fine-scale features at these interfaces. Firstly, Fig. 6a shows a $\mathrm{Cr}$ - and O-rich region directly above the metal; by examination of the proximity histogram, the stoichiometry approaches a 2:3 metal/ oxygen ratio, as expected for a protective chromia layer. The interfacial region is approximately $8 \mathrm{~nm}$ thick in total. Only trace levels of $\mathrm{Al}$ and $\mathrm{Ti}$ (1.7 and 1.1\%, respectively) are otherwise located in this oxide layer, while there also is a small region consisting solely of $\mathrm{Si}$ and $\mathrm{O}$ (1:2 ratio) at the top of the atom map.

The EPMA maps of Figs. 2 and 3 suggest that a discontinuous, localised Nb-rich phase is sometimes present beneath the chromia scale. The second APT analysis clearly backs this up, with the atom map in Fig. 6a showing an oxide that contains more $\mathrm{Nb}$ than $\mathrm{Cr}$. The $\mathrm{Nb} / \mathrm{O}$ ratio is close to $2: 5$, indicating formation of the stable oxide $\mathrm{Nb}_{2} \mathrm{O}_{5}$. This oxide is not as pure as the chromia layer, however, containing $11.8 \% \mathrm{Cr}$ along with trace levels of $\mathrm{Mo}$ and $\mathrm{Ni}(0.8$ and $0.7 \%$, respectively).

Finally, the composition of the depleted zone directly beneath the oxides can be accurately quantified, and this is compared with a measurement taken from an unused Inconel 625 sample in Table 2. The APT-derived composition of the unused sample is in excellent agreement with the XRF measurements in Table 1. However, below both oxides a depleted zone is present in which the alloy composition contains much more $\mathrm{Ni}$, mainly at the expense of $\mathrm{Cr}$. Fe levels appear unchanged approaching the interface, while the other major alloying species, Mo, has approximately doubled in concentration compared with the bulk. Both regions also show the presence of dissolved elemental oxygen in the form of a gradient beneath 
(a)
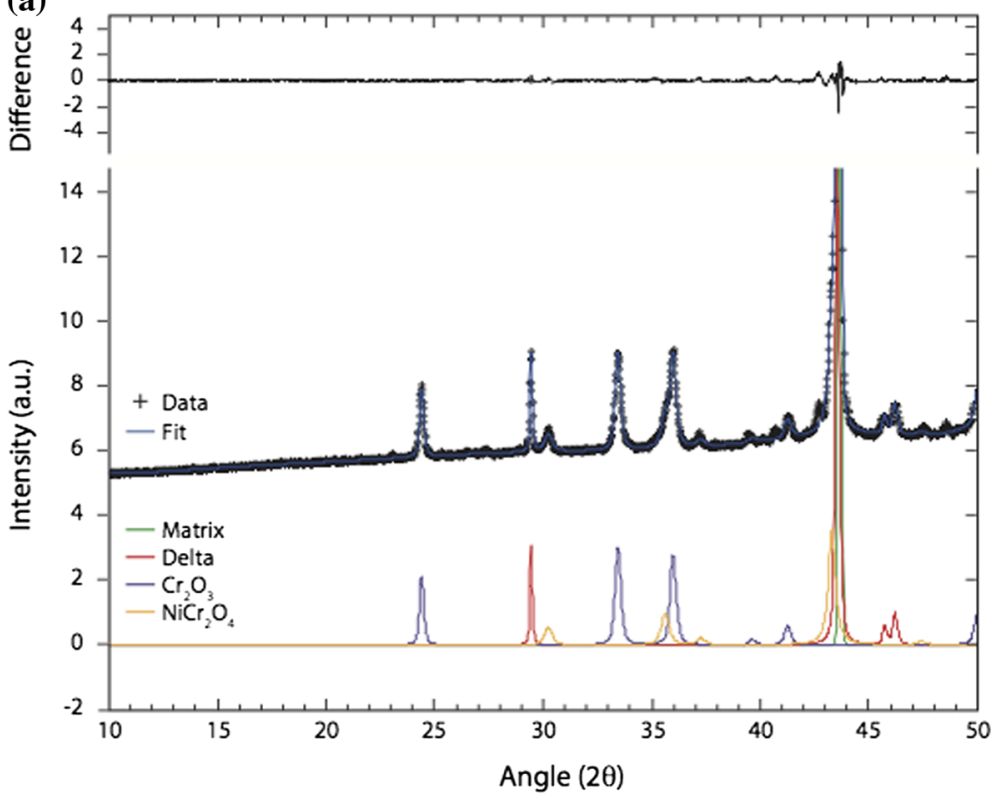

(b)
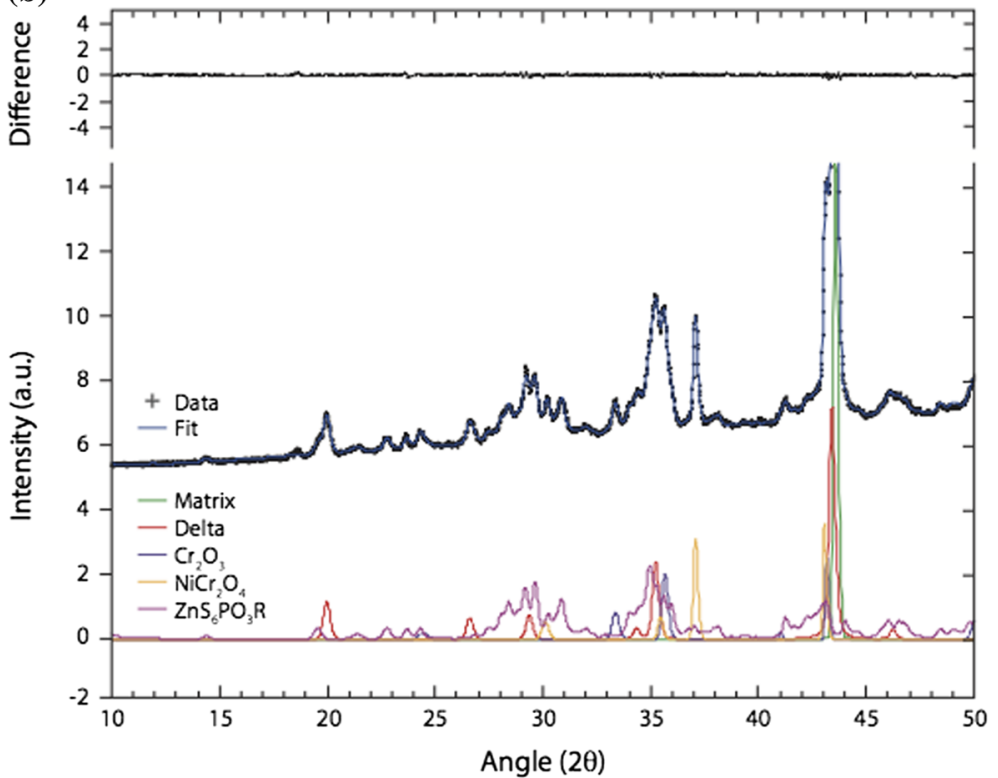

Fig. 5 Experimental X-ray diffractograms and associated fits from $\mathbf{a}$ the outer exhaust surface and $\mathbf{b}$ the inner exhaust surface

the oxide scale. None of the other metals or contaminant species identified in the EPMA data in Fig. 2 were identified in the APT analyses, because the field of view is restricted to $<100 \mathrm{~nm}$. 
Table 2 APT-derived compositions of Inconel 625, from an unused strip sample, and from the two metal regions identified in the atom maps of Fig. 6

\begin{tabular}{|c|c|c|c|c|c|c|c|c|c|c|c|}
\hline at. $\%$ & $\mathrm{Ni}$ & $\mathrm{Cr}$ & $\mathrm{Fe}$ & Mo & $\mathrm{Nb}$ & Co & $\mathrm{Mn}$ & $\mathrm{Al}$ & $\mathrm{Ti}$ & $\mathrm{Si}$ & $\mathrm{O}$ \\
\hline Unused & 61.9 & 24.4 & 4.6 & 5.8 & 1.8 & 0.1 & 0.05 & 0.6 & 0.5 & 0.3 & - \\
\hline Sub- $\mathrm{Cr}_{2} \mathrm{O}_{3}$ & 76.3 & 4.1 & 5.5 & 9.8 & 2.1 & 0.1 & - & - & 0.3 & - & 1.0 \\
\hline Sub- $\mathrm{Nb}_{2} \mathrm{O}_{5}$ & 78.3 & 0.6 & 6.0 & 11.5 & 1.4 & 0.1 & - & - & - & - & 1.9 \\
\hline
\end{tabular}

(a)
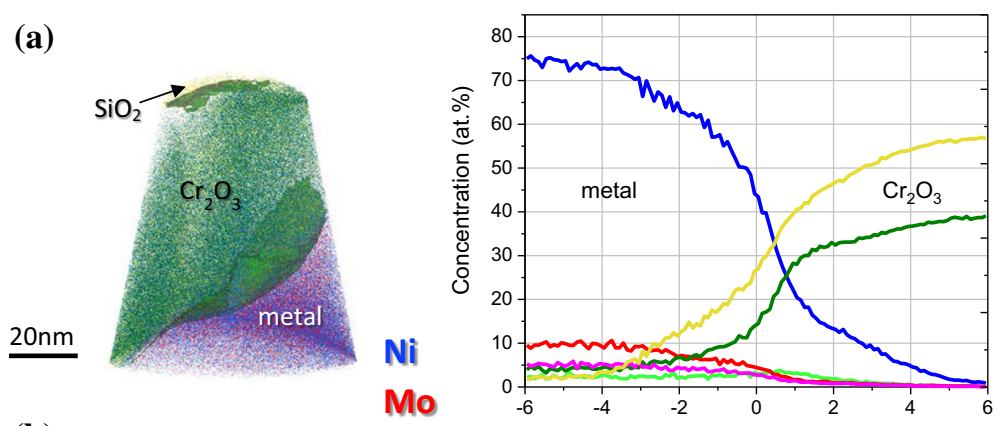

(b)
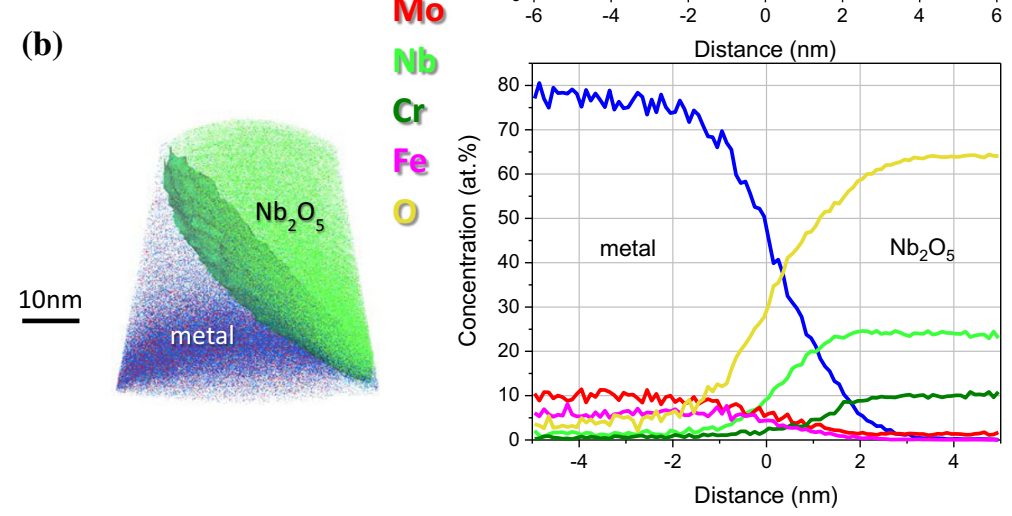

Fig. 6 APT reconstructions of oxide-metal interfaces showing atom maps and associated proximity histograms through a $\mathrm{Cr}_{2} \mathrm{O}_{3}-$ metal and $\mathbf{b ~} \mathrm{Nb}_{2} \mathrm{O}_{5}$-metal interfaces

\section{Exhaust Contaminants}

The exhaust flow contains a mix of gases and trace species generated during the combustion process. The detailed distribution of these on the inner exhaust surface is shown in Fig. 7. The structure of the contaminated oxide layer is displayed in the secondary electron (SE) image, along with a series of EDX elemental maps from the same region. A large pore is visible in the centre of the oxide, along with cracks running perpendicular to the interface.

Figure 7 underlines the inhomogeneous nature of the oxide; the brightly imaging features in the SE image are shown as Ni rich in the associated EDX map, while contamination by $\mathrm{Zn}, \mathrm{P}$ and $\mathrm{K}$ is more evenly distributed throughout. $\mathrm{Ca}$, in 


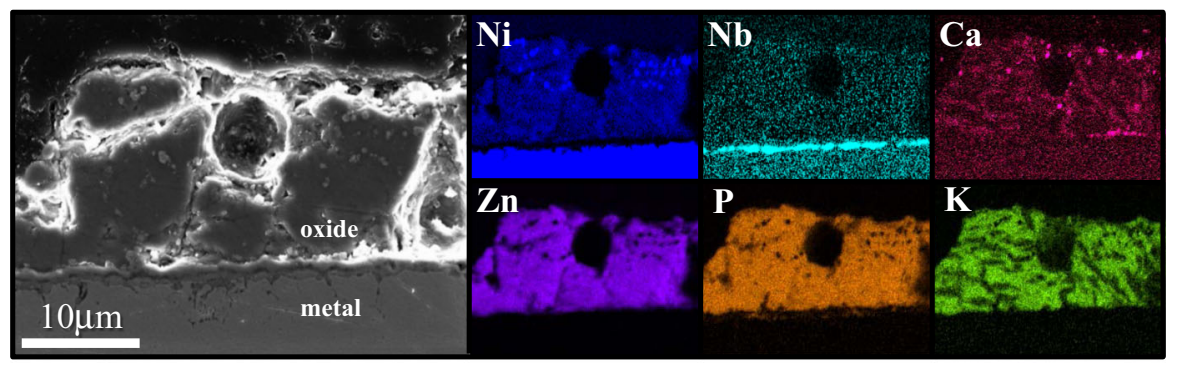

Fig. 7 SE image and EDX elemental maps of contaminant species from exhaust inner surface ( $\mathrm{Ni}, \mathrm{Nb}$, $\mathrm{Zn}$ signals from $\mathrm{L}_{\alpha} \mathrm{X}$-ray emission lines, $\mathrm{Ca}, \mathrm{P}, \mathrm{K}$ from $\mathrm{K}_{\alpha} \mathrm{X}$-ray emission lines)

contrast, is scattered in regions of the oxide. Trace levels of $\mathrm{Na}, \mathrm{Cu}$ and $\mathrm{Mg}$ were also detected by EDX. The Nb-rich layer, which demarcates the oxide-metal interface, shows that all contaminants appear confined to the oxide. Within the oxide itself, EDX line scans confirmed that $\mathrm{Zn}, \mathrm{P}$ and $\mathrm{K}$ were the three main contaminants (comprising around 30 at. $\%$ of the oxide). A significant fraction of the inner surface scale is therefore non-alloy species, which confirms the X-ray diffraction results shown in Fig. 5. Within the bulk, all three elements combined make up $<1$ at. $\%$ of the total composition.

To verify the presence of these unexpected species, along with providing a high sensitivity (ppm) capability, LA-ICPMS was used to examine the inner exhaust surface. Measurements were made on the oxide layer itself, on a side profile region below the oxide, and on the unused control sample. Along with the necessary glass standards, Fe was used as an internal standard for metal regions, while Al was used for the oxide. Suitably low, constant levels of both these elements in the respective regions were confirmed by EPMA/APT.

Figure 8a shows that all alloying species are present in the oxide. For major elements, there is approximately half as much $\mathrm{Cr}$ and $\mathrm{Mo}$ in the oxide compared to the subsurface/bulk. Comparing the subsurface metal region with that of the bulk sample, there is less $\mathrm{Ti}$ near the oxide, which may be indicative of this element being caught up in other phases. The minor element, Co, is also depleted leading up to the oxide. It is possible that the relative thermodynamic volatility of Co oxide accounts for its loss [6]. The enrichment of Si near/inside the oxide scale should also be noted, consistent with the EPMA data of Fig. 2 and prior spectroscopic measurements [8].

The contaminants identified in the same three regions are shown in Fig. $8 \mathrm{~b}$. Within the oxide, ten contaminants were identified on the inner exhaust surface, underlining the range of species present in the gas stream. The major one found is $\mathrm{Zn}$, over 9 at.\% in the oxide, and then in decreasing order (all at.\%): $\mathrm{P}(3.5 \%), \mathrm{K}$ (2\%), $\mathrm{Na}(1 \%), \mathrm{Cu}(0.5 \%), \mathrm{Ca}(0.1 \%)$. Phosphorus was present as a trace element $(\sim 100 \mathrm{ppm})$ in the base alloy, but these results suggest that it has migrated towards the surface deposit. In addition, $\mathrm{Zn}, \mathrm{P}$ and $\mathrm{K}$ seem to be mostly involved in nickel dissolution from the substrate, rather than chromium. There is also approximately 250 ppm $\mathrm{Mg}$, and sub-100 ppm levels of are $\mathrm{Pb}, \mathrm{Ba}$ and $\mathrm{S}$ present. The relative 


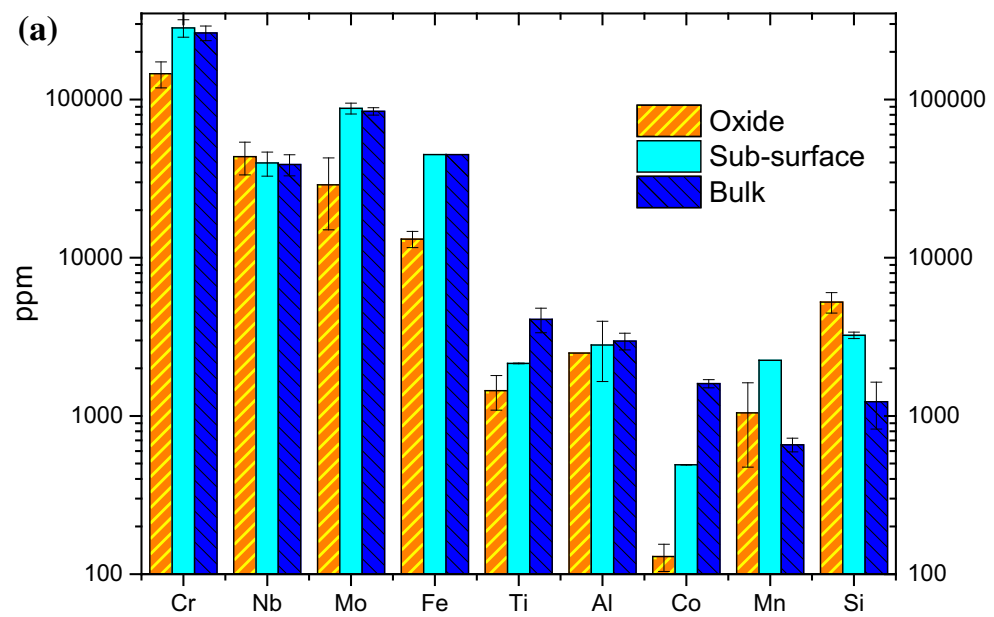

(b)

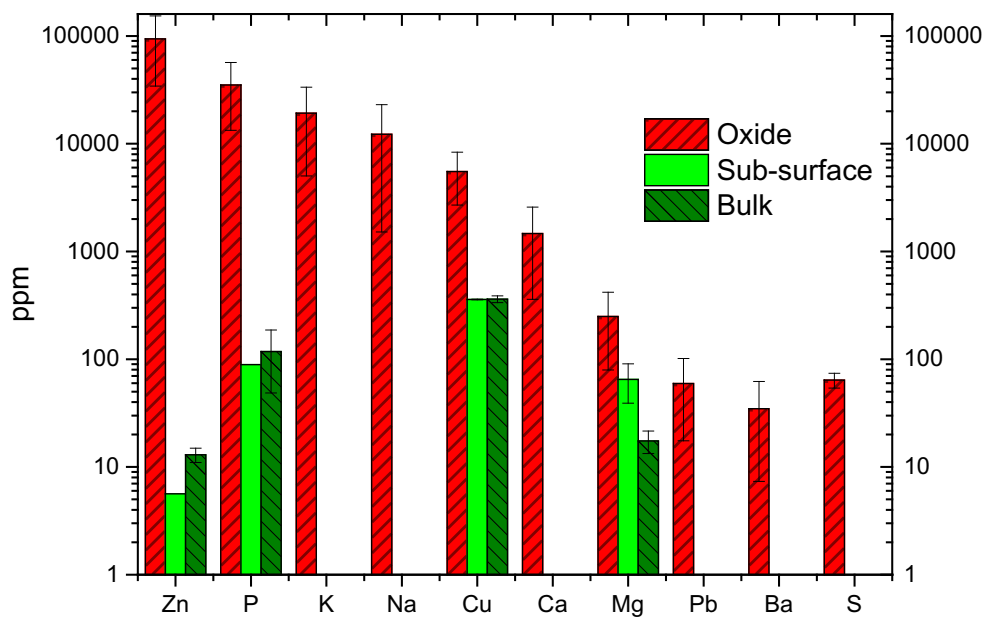

Fig. 8 LA-ICPMS analyses of oxide, near-surface and bulk regions from the inner exhaust surface for a Inconel 625 elements and $\mathbf{b}$ detected contaminants. Note $\log _{10}$ scale on both y-axes

amounts of the main contaminants detected in the oxide are thus in good agreement with those seen by EDX. In the subsurface region and even in the unused bulk control sample, trace levels of $\mathrm{Cu}(350 \mathrm{ppm})$, along with sub-100 ppm levels of $\mathrm{Zn}$, $\mathrm{P}$ and $\mathrm{Mg}$, were also identified, indicating possible introduction of these species during alloy production.

\section{Bulk Precipitates}

Below the oxide-metal interface, within the bulk, the microstructure contains a number of large blocky precipitates. An SEM-EDX examination of a region containing one such typical precipitate is shown in Fig. 9. 


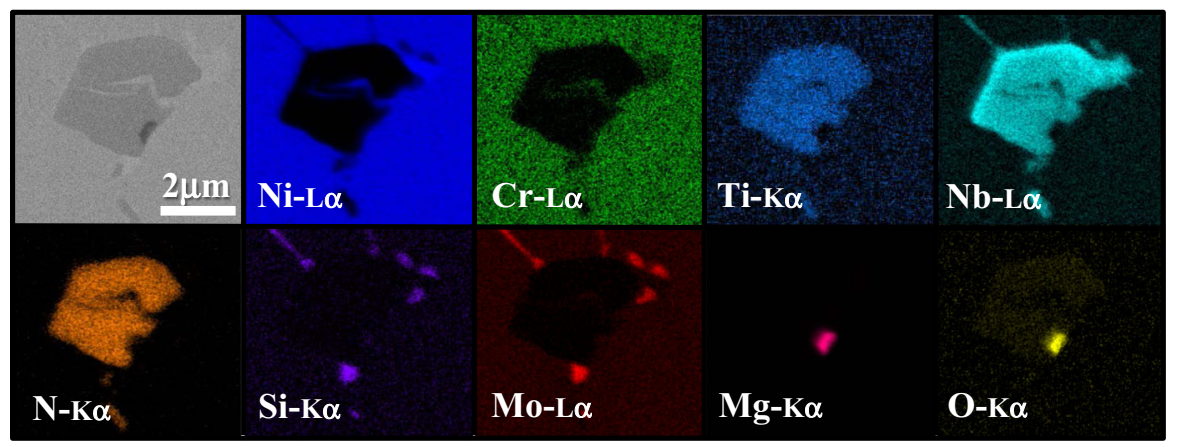

Fig. 9 EDX elemental maps of a bulk subsurface precipitate in the oxidised alloy

The BSE images show they are partially fragmented, with distinct cracks suggesting they were originally present during alloy sheet processing. They are depleted in $\mathrm{Ni}$ and $\mathrm{Cr}$ with respect to the matrix and strongly enriched in $\mathrm{Ti}, \mathrm{N}$ and $\mathrm{Nb}$. These are therefore likely to be $(\mathrm{Ti}, \mathrm{Nb})$ nitrides. The perimeters of both the particles shown in Fig. 9 are populated by smaller precipitates of two types: one rich in $\mathrm{Mo}, \mathrm{Si}$ and containing minor levels of $\mathrm{Nb}$ and the other ( $\mathrm{Nb}$ map in the top right corner of Fig. 9) enriched in $\mathrm{Ni}$ and $\mathrm{Nb}$, most likely $\delta$ phase. A fourth precipitate type is also present, imaging darkest in the BSE images at the interface between the $(\mathrm{Ti}, \mathrm{Nb})$ nitrides and the matrix. From the elemental maps, these are nanoscale $\mathrm{MgO}$ particles.

To clarify the origins of the identified phases, unused control sections of Inconel 625 were also examined. Figure 10 compares two low-magnification BSE images from the bulk regions of (a) the oxidised exhaust and (b) unused material. In both, distinct nitride features are apparent, which appear cracked and mainly arranged in bands.

Additional analytical SEM-EDX studies of the unused material revealed the presence of $\mathrm{MgO}$ close to some of these nitrides, confirming the contamination was introduced during alloy processing. However, there are two clear differences between the oxidised and unused microstructures: firstly, no evidence of Mo, Si-rich

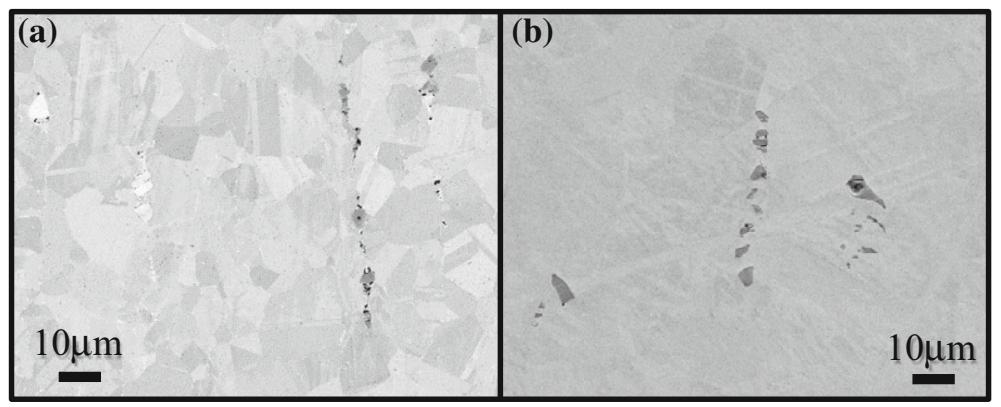

Fig. 10 BSE images from central regions of $\mathbf{a}$ oxidised and $\mathbf{b}$ unused alloy, showing bands of nitrides in both 
precipitates was seen in the unused material, indicating these are likely to have formed during exposure. The second difference is illustrated in Fig. 11; Nb-based carbides are also routinely observed in the unused material. Semiquantitative EDX analysis indicates an approximate composition of $41 \mathrm{Nb}-55 \mathrm{C}-4 \mathrm{Ti}$, consistent with MC-type carbides [21]. Additionally, the nitrides at this stage mainly contain only $\mathrm{Ti}$ as metallic species present (Fig. 11), rather than the mixture of $\mathrm{Ti}, \mathrm{Nb}$ observed in the exposed alloy, indicating the exact nitride composition is variable and dependent on the exposure history.

\section{Discussion}

\section{Oxidation Conditions}

Although the exposure environment was highly dynamic, it is possible to deduce further details of the likely conditions experienced by comparing the (contaminantfree) exhaust outer surface to model studies on the same alloy. A useful reference study was performed by Kumar et al. [6], who examined the oxidation response at $600-1250{ }^{\circ} \mathrm{C}$ in air. In their work, XPS/EDX data showed that when the temperature exceeded $1000{ }^{\circ} \mathrm{C}$ over 150 min treatments, $\mathrm{Nb}$ and $\mathrm{Ti}$ were seen in the surface oxide. The EPMA map of Fig. 2 shows the presence of some $\mathrm{Ti}$ in the oxide, while the LA-ICPMS data (Fig. 7) identifies both $\mathrm{Nb}$ and $\mathrm{Ti}$ in this region, indicating that $1000{ }^{\circ} \mathrm{C}$ was attained. Further evidence for this comes from the work by Chyrkin et al. [8]. Following a 1000-h furnace treatment at $900{ }^{\circ} \mathrm{C}$, their EDX analyses showed two bulk precipitates, one rich in $\mathrm{Ni}$ and $\mathrm{Nb}$, and the other (smaller $<1 \mu \mathrm{m} \mathrm{dia}$.) enriched in $\mathrm{Ni}$, Mo and $\mathrm{Si}$. At $1000{ }^{\circ} \mathrm{C}$, however, they reported that only the second was retained. The lower-temperature precipitate was identified as $\delta$-phase $\mathrm{Ni}_{3} \mathrm{Nb}$. From the known time-temperature transformation diagram for this alloy, $\delta$ phases begin to dissolve at $900{ }^{\circ} \mathrm{C}$ after $\sim 30 \mathrm{~h}$, becoming completely unstable at $1000{ }^{\circ} \mathrm{C}$ [21]. In the current work, $\delta$ phases were observed through X-ray diffraction. Thus, both model studies are consistent with the view that the exhaust section was operating at $1000{ }^{\circ} \mathrm{C}$ for a proportion of the time in use.

In terms of the total depth of thermally grown oxide damage, the inner and outer exhaust surfaces display similar trends, with a thin protective chromia scale above a

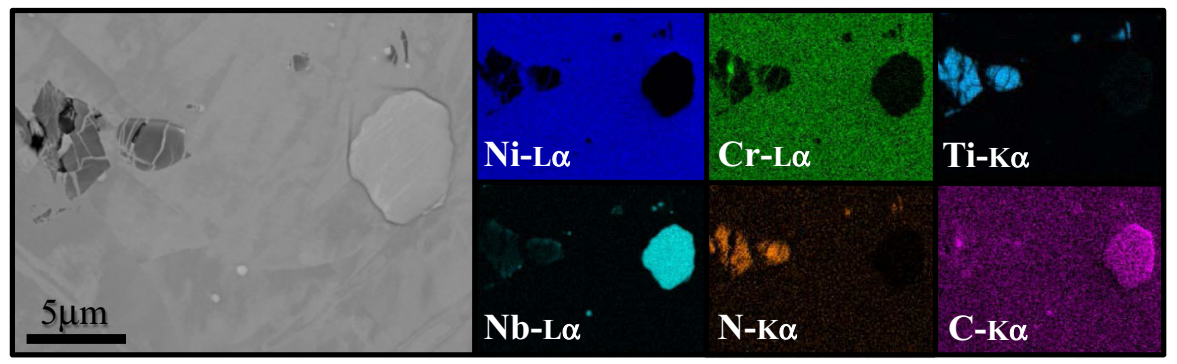

Fig. 11 EDX maps of nitride (left) and carbide (right) particles present in unused alloy 
precipitate-depleted zone some 5-6 $\mu \mathrm{m}$ deep, a closely comparable microstructure to that seen following air exposure in a previous study [8]. This previous study demonstrated parabolic oxidation rates at $900{ }^{\circ} \mathrm{C}$ over $100-1000 \mathrm{~h}$, while weight gain measurements have also shown parabolic oxidation in this alloy up to $1150{ }^{\circ} \mathrm{C}$ [6]. Thus, it seems while the environment is much more complex in the current work, the kinetics of subsurface microstructural changes are similar to that of pure air exposures. However, the oxide layer itself on the inner surface is approximately 3-4 times thicker than that on the outer surface, signifying significantly accelerated corrosion when the surface is exposed to a dynamic, combustion productcontaminated environment and water vapour. Water vapour is likely to have been in contact with the inner exhaust surface, which is known to substantially increase the thickness of the chromia scale formed on nickel superalloys and steels [22, 23]. The relative volatility of chromium hydroxides formed during water vapour exposures may also cause faster corrosion of the exposed surface [24].

A final feature of note in this region is the strong $\mathrm{Nb}$ enrichment directly beneath the oxide scale. Similar enrichment has also been documented in previous experimental and thermodynamic modelling studies on oxidised Inconel 625 and 718 alloys [8, 25-27]. Chyrkin et al. [8] reported the formation of a localised $\delta$ phase within the denuded zone beneath the oxide scale, not seen in the bulk. The XRD data highlighting the existence of $\delta$ phase will certainly be sampling this nearsurface area, although the APT data indicate that $\mathrm{Nb}$ near the interface may also be present in an oxide form.

\section{Contaminants}

The oxide scale is up to $3-4 \times$ thicker on the inner manifold surface than the outer one, with a highly inhomogeneous composition containing significant levels of $\mathrm{Zn}$, $\mathrm{P}, \mathrm{K}$ and $\mathrm{Na}$ throughout and localised regions rich in $\mathrm{Ca}, \mathrm{Cu}$ and $\mathrm{Mg}$. The presence of alloying elements in this thicker oxide indicates that contaminants are further accelerating oxidative attack of the surface. This may lead to component lifetimes being overestimated using studies relying on model exposures to oxygen. The range of contaminants detected also offers an insight into the performance of the overall engine system. Many of these likely originate from engine lubricants passing through to the engine fuel side; zinc dialkyldithiophosphate (ZDDP) is a common additive, which could account for the high levels of $\mathrm{Zn}$ and $\mathrm{P}$ co-located in the oxide. If this contamination affected a road vehicle, poisoning of the catalytic converter could occur [28, 29], leading to increased emissions. $\mathrm{K}$ and $\mathrm{Ca}$ are also used in engine additives, with the levels present in exhaust particulates correlated to engine load conditions [30, 31]. Na may be introduced through leakage from coolants or salt water, with the latter leading to accelerated corrosion, while trace $\mathrm{Cu}$ may be indicative of wear in the engine bearings. While analysis of the combustion gases was not available, such engines run on petrol similar to that in road-going vehicles. The current regulations for the sport limit any impurities of such metals to less than $1 \%$ of the total mass of the fuel [32], but an in-depth study to correlate source with deposition level in the exhaust may provide valuable further information on the evolution of the combustion system, and additionally for road 
vehicles such levels may correlate with results from atmospheric emissions monitoring.

\section{Precipitate Evolution}

Using a combination of EDX and ThermoCalc modelling, Chyrkin et al. [8] suggested the higher-temperature grain boundary precipitates were $\mathrm{M}_{6} \mathrm{C}$ carbides, rich in $\mathrm{Mo}$ and $\mathrm{Ni}$, with trace amounts of $\mathrm{Cr}, \mathrm{Nb}$ and $\mathrm{Si}$. However, carbon could not be unequivocally identified. Additionally, the authors reported that ThermoCalc dramatically underestimates the Si level in any carbides, noting Si contents as high as 12 at.\% have been observed experimentally [33]. Furthermore, Floreen et al. [21] suggest that Si may in fact promote the nucleation of $\mathrm{M}_{6} \mathrm{C}$, although a mechanism for this process requires further research. In the current work, we do not detect carbon segregation in the Mo, Si-rich phases that decorate grain boundaries and the nitrides; therefore, we cannot confirm they are carbides. Silicides have not been reported previously in Ni-based superalloys. However, $\mathrm{Mo}_{5} \mathrm{Si}_{3}$ is a known thermodynamically stable species $\left(\Delta G_{f}=-319 \mathrm{~kJ} / \mathrm{mol}\right.$ at $1273{ }^{\circ} \mathrm{C}$ [34] $)$, and the formation of $(\mathrm{Nb}, \mathrm{Mo})_{5} \mathrm{Si}_{3}$ silicides has been observed in high Si-content $\mathrm{Nb}$-based alloys [35]. Prior studies have examined the effects of Si addition on superalloy properties [36, 37], but the partitioning behaviour of Si to $\gamma$ or $\gamma^{\prime}$ phases appears to change with different alloying additions (such as Ti). Whilst the addition of $\mathrm{Si}$ is known to improve oxidation resistance $[33,37]$ and mechanical properties such as thermal-mechanical fatigue [38] in single-crystal alloys, Si segregates to grain boundaries and has been known to trigger the formation of topologically closepacked (TCP) phases in polycrystalline alloys [38]. Floreen et al. [21] outlined the structures and typical compositions of grain boundary precipitates in Inconel 625 during thermal exposures, placing $\mathrm{Si}$ either in the $\mathrm{M}_{6} \mathrm{C}$ carbides or in TCP (Laves) phases with a composition of $\left(\mathrm{Cr}_{0.31} \mathrm{Fe}_{0.08} \mathrm{Ni}_{0.41}\right)_{2}\left(\mathrm{Si}_{0.17} \mathrm{Ti}_{0.01} \mathrm{Nb}_{0.19} \mathrm{Mo}_{0.13}\right)$. At this stage, further high-resolution characterisation is thus required to confirm the exact chemical composition and crystal structure of the Mo, Si precipitates, including how their composition may evolve during ageing.

An additional fate for $\mathrm{Si}$ is to migrate towards the oxide-metal interface, as shown in the EPMA maps (Figs. 2, 3) forming near-continuous layers under the chromia scale. Si has been shown to promote the formation of continuous, stable scales of chromia, alumina or (when present in sufficient quantities) silica. The APT data shown in Fig. 5b confirm that silicon oxides are indeed forming, even if only at levels detectable using sub-nm resolution. All of these scales are more protective than the transient oxides that would otherwise form [39], underlining the benefits to oxidation resistance [36-38] and the need for further dedicated studies on the effect of Si content.

The larger blocky precipitates in the unused alloy are Nb-based MC carbides, which are known to precipitate from the solidification process [21]. While much less work has been done to fully understand the role of nitrogen in superalloys, TiN is a stable nitride [34], and a recent study has shown nitrogen preferentially bonds with $\mathrm{Ti}$ and $\mathrm{Nb}$ atoms to form nitrides [18]. In the current work, the exposure appears to cause dissolution of the Nb-based MC carbides, which have been previously thought 
very difficult to remove by processing [21]. The released $\mathrm{Nb}$ appears to be absorbed by preexisting $\mathrm{Ti}$ nitrides to form mixed $(\mathrm{Ti}, \mathrm{Nb}) \mathrm{N}$ species. These preexisting nitrides likely form in the liquid alloy during cooling, becoming aligned into bands during sheet rolling of the metal. The generation of brittle, blocky, incoherent precipitate bands during rolling can locally concentrate applied stresses, acting as favourable crack nucleation sites and increasing the effect of thermal stresses (reducing ductility) perpendicular to the loading direction [21]. Controlling the levels of nitrogen introduced during processing, the extent of initial $\mathrm{NbC}$ formation or even slightly reducing the amount of $\mathrm{Nb}$ may prevent these forming and give better mechanical properties, increasing the short operational lifetime of the exhaust manifolds. Even reductions in $\mathrm{Nb}$ of $<0.5 \mathrm{wt} \%$ have been shown to significantly extend the time before the alloy starts to embrittle at high temperatures [40]. Therefore, small adjustments in the concentration of $\mathrm{Nb}$ present in the alloy may prove highly effective in specific applications.

\section{Conclusions}

The chemical and microstructural changes to an Inconel 625 exhaust manifold have been examined in detail following in-service use within a high-performance vehicle environment. We have demonstrated that the use of detailed multi-technique analysis on in-service components provides a wealth of data, vital in order to understand the effects of composition, processing routes and environmental exposures and therefore design higher-performance alloys specifically optimised for their operating environments. From this study, the following specific conclusions can be drawn: the oxide on the inner exhaust surface is 3-4 times thicker than on the outer surface, indicating accelerated oxidative attack from exhaust gases, and the inner oxide scale was shown to be heavily contaminated with numerous species including $\mathrm{Zn}, \mathrm{P}, \mathrm{K}, \mathrm{Na}$, along with lower levels of $\mathrm{Cu}, \mathrm{Ca}$ and $\mathrm{Mg}$, none of which were present in the alloy before exposure. However, the formation of the protective chromia scales and $\mathrm{Ni}, \mathrm{Cr}$ spinels was found to be consistent between both the operating environments investigated in this study and the isothermal exposures available in the literature. The inner and outer surfaces of the exhaust display similar microstructural features below the oxide scales, with the exposure inducing the dissolution of $\mathrm{NbC}$ carbides and the formation of mixed $(\mathrm{Ti}, \mathrm{Nb}) \mathrm{N}$ nitrides. Precipitation of $\mathrm{Mo}$, Si-rich features on the edges of these nitrides and at grain boundaries also occurs in service. The microstructural characterisation, revealing in particular the onset of $\delta$-phase formation, is consistent with the view that this section of the exhaust has at least periodically experienced temperatures up to $1000{ }^{\circ} \mathrm{C}$ during operation, above the recommended levels for this alloy.

Acknowledgements We would like to dedicate this publication in memory of our co-author Gabriella Chapman, who sadly passed away while this manuscript was in preparation. LA-ICPMS experiments were carried out in the Department of Earth Sciences with thanks to Prof. Bernard Wood, financially supported by ERC Grant 267764. E.S. Kiseeva was supported by NERC Grant NE/L010828/ 1. Additional EPMA experiments were carried out at the School of Geosciences, University of 
Edinburgh with thanks to Dr. Chris Hayward. A. Radecka was supported by Prof. David Dye at Imperial College London and Prof. Dave Rugg in Rolls-Royce plc. for facilities to prepare samples.

Open Access This article is distributed under the terms of the Creative Commons Attribution 4.0 International License (http://creativecommons.org/licenses/by/4.0/), which permits unrestricted use, distribution, and reproduction in any medium, provided you give appropriate credit to the original author(s) and the source, provide a link to the Creative Commons license, and indicate if changes were made.

\section{References}

1. T. M. Pollock and S. Tin, Nickel-based superalloys for advanced turbine engines: chemistry, microstructure and properties. Journal of Propulsion and Power 22, 2006 (361-374). doi:10.2514/1. 18239.

2. R. C. Reed, The Superalloys-Fundamentals and Applications, (Cambridge University Press, Cambridge, 2006).

3. F. Curà, A. Mura and R. Sesana, Aging characterization of metals for exhaust systems. International Journal of Automotive Technology 13, 2012 (629-636). doi:10.1007/s12239.

4. T. Chen, J. Nutter, J. Hawk and X. Liu, Corrosion fatigue crack growth behavior of oil-grade nickelbase alloy 718. Part 1: effect of corrosive environment. Corrosion Science 89, 2014 (146-153). doi:10.1016/j.corsci.2014.08.022.

5. M. Meisnar, M. Moody and S. Lozano-Perez, Atom probe tomography of stress corrosion crack tips in SUS316 stainless steels. Corrosion Science 98, 2015 (661-671). doi:10.1016/j.corsci.2015.06.008.

6. L. Kumar, R. Venkataramani, M. Sundararaman, P. Mukhopadhyay and S. P. Garg, Studies on the oxidation behavior of Inconel 625 between 873 and 1523 K. Oxidation of Metals 45, 1996 (221-244). doi:10.1007/BF01046827.

7. A. Vesel, A. Drenik, K. Elersic, M. Mozetic, J. Kovac, T. Gyergyek, J. Stockel, J. Varju, R. Panek and M. Balat-Pichelin, Oxidation of Inconel 625 superalloy upon treatment with oxygen or hydrogen plasma at high temperature. Applied Surface Science 305, 2014 (674-682). doi:10.1016/j.apsusc. 2014.03.160.

8. A. Chyrkin, P. Huczkowski, V. Shemet, L. Singheiser and W. J. Quadakkers, Sub-scale depletion and enrichment processes during high temperature oxidation of the nickel base alloy 625 in the temperature range $900-1000{ }^{\circ} \mathrm{C}$. Oxidation of Metals 75, 2011 (143-166). doi:10.1007/s11085-0109225-3.

9. G. Bertali, F. Scenini and M. G. Burke, Advanced microstructural characterization of the intergranular oxidation of alloy 600. Corrosion Science 100, 2015 (474-483). doi:10.1016/j.corsci.2015. 08.010 .

10. G. A. Greene and C. C. Finfrock, Oxidation of Inconel 718 in air at high temperatures. Oxidation of Metals 55, 2001 (505-521).

11. K. A. Al-hatab, M. A. Al-bukhaiti, U. Krupp and M. Kantehm, Cyclic oxidation behavior of IN 718 superalloy in air at high temperatures. Oxidation of Metals 75, 2011 (209-228). doi:10.1007/s11085010-9230-6.

12. M. S. Bakare, K. T. Voisey, M. J. Roe and D. G. McCartney, X-ray photoelectron spectroscopy study of the passive films formed on thermally sprayed and wrought Inconel 625. Applied Surface Science 257, 2010 (786-794). doi:10.1016/j.apsusc.2010.07.066.

13. D. Seo, M. Sayar and K. Ogawa, $\mathrm{SiO}_{2}$ and $\mathrm{MoSi}_{2}$ formation on Inconel 625 surface via SiC coating deposited by cold spray. Surface and Coatings Technology 206, 2012 (2851-2858). doi:10.1016/j. surfcoat.2011.12.010.

14. E. Mohammadi Zahrani and A. M. Alfantazi, Molten salt induced corrosion of Inconel 625 superalloy in $\mathrm{PbSO}_{4}-\mathrm{Pb}_{3} \mathrm{O}_{4}-\mathrm{PbCl}_{2}-\mathrm{Fe}_{2} \mathrm{O}_{3}-\mathrm{ZnO}$ environment. Corrosion Science 65, 2012 (340-359). doi:10.1016/j.corsci.2012.08.035.

15. L. Jian, C. Y. Yuh and M. Farooque, Oxidation behavior of superalloys in oxidizing and reducing environments. Corrosion Science 42, 2000 (1573-1585). doi:10.1016/S0010-938X(00)00011-1. 
16. D. Haley, P. A. J. Bagot and M. P. Moody, Atom probe analysis of ex situ gas-charged stable hydrides. Microscopy and Microanalysis 2017. doi:10.1017/S1431927616012630.

17. E. Bassoli, N. Sewell, L. Denti and A. Gatto, Investigation into the failure of Inconel exhaust collector produced by laser consolidation. Engineering Failure Analysis 35, 2013 (397-404). doi:10. 1016/j.engfailanal.2013.03.025.

18. J. B. Singh, A. Verma, B. Paul and J. K. Chakravartty, Failure of alloy 625 tube stub ends-effect of primary nitrides. Engineering Failure Analysis 32, 2013 (236-247). doi:10.1016/j.engfailanal.2013. 03.018 .

19. G. Cliff and G. W. Lorimer, The quantitative analysis of thin specimens. Journal of Microscopy 103, 1975 (203-207). doi:10.1111/j.1365-2818.1975.tb03895.x.

20. D. W. Saxey, J. M. Cairney, D. McGrouther, T. Honma and S. P. Ringer, Atom probe specimen fabrication methods using a dual FIB/SEM. Ultramicroscopy 107, 2007 (756-760). doi:10.1016/j. ultramic.2007.02.024.

21. S. Floreen, G. E. Fuchs and W. J. Yang, The metallurgy of alloy 625. Superalloys 718, (625), 1994 (706). doi:10.7449/1994/Superalloys_1994_13_37.

22. K. Onal, G. H. Meier and F. S. Pettit, The effects of water vapor on the oxidation of nickel-base superalloys and coatings at temperatures from $700{ }^{\circ} \mathrm{C}$ to $1100{ }^{\circ} \mathrm{C}$. Proceedings of the International Symposium on Superalloys 5, 2004 (607-615).

23. J. Ehlers, D. J. Young, E. J. Smaardijk, A. K. Tyagi, H. J. Penkalla, L. Singheiser and W. J. Quadakkers, Enhanced oxidation of the $9 \% \mathrm{Cr}$ steel P91 in water vapour containing environments. Corrosion Science 48, 2006 (3428-3454). doi:10.1016/j.corsci.2006.02.002.

24. S. R. J. Saunders, M. Monteiro and F. Rizzo, The oxidation behaviour of metals and alloys at high temperatures in atmospheres containing water vapour: a review. Progress in Materials Science 53, 2008 (775-837). doi:10.1016/j.pmatsci.2007.11.001.

25. W. E. Moddeman, S. M. Craven and D. P. Kramer, $\mathrm{Ni}_{3} \mathrm{Nb}$ alloy species in oxide surfaces of inconel 718. Metallurgical and Materials Transactions A 17, 1986 (351-355).

26. F. Delaunay, C. Berthier, M. Lenglet and J. M. Lameille, SEM-EDS and XPS studies of the high temperature oxidation behaviour of Inconel 718. Microchimica Acta 132, 2000 (337-343).

27. E. N'dah, M. P. Hierro, K. Borrero and F. J. Pérez, Study of the cyclic oxidation resistance of superalloy IN-625: lifetime predicted by COSP-modelling program. Oxidation of Metals 68, 2007 (9-21). doi:10.1007/s11085-006-9048-4.

28. D. D. Beck, J. W. Sommers and C. L. Dimaggio, Axial characterization of catalytic activity in closecoupled lightoff and underfloor catalytic converters. Applied Catalysis B: Environmental 11, 1997 (257-272).

29. S. Y. Christou, S. García-Rodríguez, J. L. G. Fierro and A. M. Efstathiou, Deactivation of Pd/ $\mathrm{Ce}_{0.5} \mathrm{Zr}_{0.5} \mathrm{O}_{2}$ model three-way catalyst by $\mathrm{P}, \mathrm{Ca}$ and $\mathrm{Zn}$ deposition. Applied Catalysis B: Environmental 111-112, 2012 (233-245). doi:10.1016/j.apcatb.2011.10.004.

30. E. S. Cross, A. Sappok, E. C. Fortner, J. F. Hunter, J. T. Jayne, W. A. Brooks, T. B. Onasch, V. W. Wong, A. Trimborn, D. R. Worsnop and J. H. Kroll, Real-time measurements of engine-out trace elements : application of a novel soot particle aerosol mass spectrometer for emissions characterization. Journal of Engineering for Gas Turbines and Power 134, 2012 (072801).

31. A. K. Agarwal, Particulate characterization and size distribution in the exhaust of a gasoline homogeneous charge compression ignition engine. Aerosol and Air Quality Research 15, 2015 (504-516). doi:10.4209/aaqr.2014.01.0021.

32. Fédération Internationale de L'Automobile, Formula One Sporting Regulations (2016).

33. S. Hamar-Thibault, N. Valignat, S. Lebaili, Composition of M6C carbides formed in nickel-based hardfacing alloys, in: X-Ray Opt. Microanal. 1992, eds. P. B. Kenway and P. J. Duke (Institute of Physics Conference Series, 1993), pp. 189-192.

34. W. F. F. Gale and T. C. C. Totemeier, Smithells Metals Reference Book, 8th ed, (Elsevier Butterworth Heinemann Ltd, Oxford, 2004).

35. K. S. Thomas and S. K. Varma, Oxidation response of three $\mathrm{Nb}-\mathrm{Cr}-\mathrm{Mo}-\mathrm{Si}-\mathrm{B}$ alloys in air. Corrosion Science 99, 2015 (145-153). doi:10.1016/j.corsci.2015.06.026.

36. A. C. Yeh, K. C. Yang, J. W. Yeh and C. M. Kuo, Developing an advanced Si-bearing DS Ni-base superalloy. Journal of Alloys and Compounds 585, 2014 (614-621). doi:10.1016/j.jallcom.2013.09. 193.

37. D. W. Yun, S. M. Seo, H. W. Jeong and Y. S. Yoo, The effects of the minor alloying elements Al, Si and $\mathrm{Mn}$ on the cyclic oxidation of Ni-Cr-W-Mo alloys. Corrosion Science 83, 2014 (176-188). doi:10.1016/j.corsci.2014.02.015. 
38. M. Segersäll, P. Kontis, S. Pedrazzini, P. A. J. Bagot, M. P. Moody, J. J. Moverare and R. C. Reed, Thermal-mechanical fatigue behaviour of a new single crystal superalloy: effects of $\mathrm{Si}$ and $\mathrm{Re}$ alloying. Acta Materialia 95, 2015 (456-467). doi:10.1016/j.actamat.2015.03.060.

39. A. Sato, Y. I. Chiu, E. A. Marquis and R. C. Reed, Characterisation of oxide scale formation on a new single crystal superalloy for power generation applications. Materials at High Temperatures 29, 2012 (272-278). doi:10.3184/096034012X13335334078005.

40. M. Kohler, Effect of the Elevated-Temperature-Precipitation in Alloy 625 on Properties and Microstructure, Superalloys 718, 625 and Various Derivatives, TMS, 1991, p. 363. 